\title{
Elementos padrão para a análise das contas médicas: formação da conta hospitalar
}

\author{
Adam Carlos Cruz da SILVA ${ }^{(1)}$ \\ Vivian SCHUTZ ${ }^{(1)}$ \\ (1) Universidade Federal do Estado do Rio de Janeiro - UNIRIO, Rio de Janeiro, RJ, Brasil.
}

Recebido: 28 jan 2019 Aceito: 10 fev 2019

Autor de correspondência: enfoadamcarlos@gmail.com

Conflito de interesses: Os autores declaram não haver nenhum interesse profissional ou pessoal que possa gerar conflito de interesses em relação a este manuscrito.

\section{Resumo}

Os elementos para a análise de contas médicas e hospitalares abrangem qual a pertinência para compor uma conta hospitalar, com intuito de uniformizar e dinamizar a sua estrutura. Conhecer cada elemento de sua composição e as regras de padronização é válido na confecção, na auditoria e no envio da mesma as operadoras de saúde pelos prestadores de serviços, evitando na maioria das vezes em recusa do pagamento dos serviços prestados ou reenvio das contas por modelos inadequados. Conhecer esses elementos é importante no setor, para uma padronização de sistemas de informação na área da saúde e uma melhor auditagem realizada em diversos prestadores de serviços. Como objetivo geral, analisar quais os elementos padrão para a formação da conta médica e hospitalar. Desenvolveu-se uma revisão sistemática rápida, onde foi realizada a busca de estudos sobre os elementos padrão para a análise das contas médicas e hospitalares. As buscas foram realizadas via portal Pubmed, Lilacs e Google Acadêmico entre os meses de janeiro e fevereiro de 2018. Utilizou-se para a revisão o anagrama PICO, que orienta formular a pergunta de pesquisa e realizar a busca dos descritores adequados. A pesquisa foi realizada utilizando-se os operadores booleanos " $A N D^{\prime}$ e " $O R^{\prime}$ para a associação do descritor controlado auditoria de enfermagem e os não controlados auditoria de contas médicas e hospitalares e glosa. Os critérios de inclusão aplicados foram: (1) artigos e outros achados acadêmicos publicados nos últimos 12 anos (de 2004 a 2018); (2) idiomas inglês, português e espanhol; (3) publicações disponibilizadas na íntegra; e (4) publicações que abordem o assunto auditora de enfermagem e auditoria de contas médicas e hospitalares. Como critério de exclusão aqueles artigos e publicações acadêmicas que apareceram mais de uma vez nas bases de dados. Foram encontrados no total 6.168 publicações que após a aplicação dos critérios de inclusão e exclusão foram selecionados oito estudos, em língua portuguesa, sendo quatro artigos científicos e quatro teses de mestrado, porém uma das teses converteu-se em artigo científico que foi selecionado, totalizando sete estudos. O estudo realizado por Cintra, Souza e Souza, descreve que a quantidade de instituições conveniadas e o volume de contas para serem auditadas, é essencial que estas contas estejam com todos os dados e as informações pertinentes aos tratamentos realizados. Os autores trazem a grande valia na construção deste processo que é a conta hospitalar, e enfatizam a organização e a implementação de todos os dados para que possíveis glosas não 
sejam aplicadas. O estudo de Guerrer, Castilho e Lima, orienta que o processo de formação de uma conta hospitalar inicia-se na Unidade de Faturamento (UFA) assim que o paciente proveniente da operadora de saúde ou paciente particular é internado em uma das unidades do Instituto do Coração. Há ainda outra forma de cobrança desenvolvida na UFA, que é regida por contratos firmados entre o Instituto do Coração e as Operadoras de saúde, denominados pacotes. Neste pacote, não consta o detalhamento dos itens a serem cobrados uma vez que é estabelecido um preço fechado para a realização de um dado procedimento com prazo determinado de internação. Entretanto, caso ocorram complicações clínicas decorrentes do procedimento, demandando o prolongamento da internação do paciente, torna-se necessária a abertura destas contas coma descrição dos elementos da conta hospitalar. Dentre os itens registrados pelos Auditores no estudo do Instituto do Coração, as diárias em geral (UTI, apartamento e enfermarias), taxas administrativas, exames, hemoterapia, honorários médicos, fisioterapia, verificação das autorizações da operadora de saúde para a realização dos procedimentos, dos códigos dos procedimentos que devem ser preenchidos conforme tabelas previamente acordada e a utilização de materiais de alto custo. O estudo de Junior direciona que as contas faturadas deverão ser encaminhadas para as operadoras de saúde de maneira individualizadas com as despesas e os comprovantes respectivos de acordo com as codificações da Agência Nacional de Saúde Suplementar - ANS. Essa documentação dependerá da exigibilidade de cada operadora, como exemplo as guias de solicitação, prorrogação de diárias, autorizações de materiais e medicamentos em geral, evoluções nota de sala etc. Já a conta hospitalar deverá ser preenchida com os seguintes elementos: Diárias, taxas, materiais e medicamentos utilizados, taxas de aparelhos, gases medicinais, serviço de apoio diagnóstico (SADT), honorários médicos, pedidos de exames complementares, relatórios dos profissionais envolvidos na assistência, identificação de Órteses, Próteses e Materiais Especiais (OPME) e outros documentos que a auditoria julgue necessário. Buzzi descreve que para o orçamento de um pacote hospitalar é necessário que se acrescente outras variáveis que normalmente são determinadas de acordo coma Instituição; diárias, taxas de sala cirúrgica, taxas de sala não cirúrgicas, taxas de uso de equipamentos, taxas de serviços, taxas de gases, honorários médicos e serviço auxiliar de diagnóstico e terapia (SADT). Dentre as vantagens e as desvantagens de cada tipo de conta se aberta ou fechada está à avaliação financeira de cada instituição de acordo com os seus interesses. Kobus e Dias, em seu estudo sugerem um padrão de terminologia de dados essenciais para auditoria de contas hospitalares com campo para resumo clínico de internação, identificação, dados de internação, diagnóstico, taxas, gases medicinais, exames em geral, equipamentos, materiais e medicamentos, materiais e medicamentos de alto custo, serviços em geral, honorários, procedimentos, valores referenciais, avaliação da qualidade, considerações do auditor e motivos da glosa. As diversas etapas para a formação da conta hospitalar oferecem uma oportunidade de investigação e melhoria contínua dos processos da forma de remuneração dos 
hospitais de acordo com o evento hospitalar e a previsibilidade dos processos assistenciais. Conhecer os custos de cada elemento do evento hospitalar tornase uma necessidade gerencial para a tomada de decisões quanto ao tipo de modelo de remuneração a ser aplicado. A sistemática de remuneração na saúde suplementar conforme sugerida pela ANS devem esclarecer os elementos que irão compor a conta hospitalar e novos modelos devem ser sempre pesquisados para desenvolvimento do setor.

Descritores: Auditoria de Enfermagem; Auditoria Médica; Auditoria Financeira. 